\title{
APPLICATION AND PERFORMANCE EVALUATION OF MODEL PREDICTIVE CONTROLLERS ON DRIVING FORCE BASED REACTIVE DISTILLATION PROCESSES
}

\author{
Ashfaq Iftakher, Ahaduzzaman Nahid and M.A.A.Shoukat Choudhury* \\ Bangladesh University of Engineering and Technology, Dhaka-1000, Bangladesh \\ Seyed Soheil Mansouri \\ Technical University of Denmark, DK-2800, Kongens Lyngby, Denmark \\ Rafiqul Gani \\ PSE for SPEED Company Limited, Skyttemosen 6, DK-3450 Allerod, Denmark
}

\begin{abstract}
In this work, integrated design and control of Reactive Distillation (RD) column operating under Model Predictive Controller (MPC) is presented. At first, a design target is defined, and the RD column is designed based on the element concept at the maximum driving force. After that, the steady state simulation is carried out in ASPEN PLUS that satisfies the design target. Next, the flow driven dynamic system is linearized in ASPEN PLUS Dynamics and the state space matrices are obtained. Using the matrices, MPC closed-loop simulation is carried out in MATLAB. To quantify both the steady state and dynamic operation, a multi objective function is defined that takes into account both the design (total energy consumption, total carbon footprint), and the control performance (Integral Absolute Error, total variation of input, relative gain array, Niederlinski Index). For further verification, an alternative design based on non-maximal driving force is also obtained, and the corresponding steady state and dynamic simulation is performed. The closed-loop performance of MPC controller under feed disturbance shows that the process that is designed at the maximum driving force exhibit better control performance compared to the design alternative that does not take into account the maximum available driving force.
\end{abstract}

Keywords: model predictive controller, driving force, reactive distillation, integrated design-control

\section{Introduction}

Process design and process control, if considered sequentially, generally leads to a process design that is dynamically inoperable[1]. Therefore, simultaneous consideration is necessary not only to eliminate potentially promising design alternatives with poor control performance, but also to ensure controllability and safe operation under process upset. Reactive distillation (RD) provides attractive scope of process intensification, and results into huge savings of capital cost due to the reduction of required process units. In case of design of RD systems, driving force approach[2] provides a graphical method. This approach also takes controllability into account as Mansouri et.al.[3] have previously shown that by simultaneously considering design and control issues through the driving force concept, optimal designcontrol of reactive distillation units can be achieved. However, most of the works regarding integrated design-control of $\mathrm{RD}$ involve regulatory control structures. Work on advanced controller such as MPC has scarcely been reported. One of the notable works include the methodology proposed by Francisco et al. [4] for the simultaneous design of processes and control under linear MPCs. Another work is the proposed methodology by Bahakim and Ricardezsandoval[5] which is based on stochastic simultaneous design and MPC control under uncertainty. In this work, we aim to investigate the MPC control performance of RD systems that are designed based on the driving force approach. The results reported by Mansouri et al.[3] are confirmed and extended in this work through the application of MPC.

\section{Distillation column design}

In this work, the well-known production of MTBE by reactive distillation from isobutene (i-butene) and methanol $(\mathrm{MeOH})$ is presented to highlight the steps for the integrated process design and control under MPC. The reaction of methanol with isobutene yields MTBE and can be expressed as follows: 


$$
\text { i-butene }+\mathrm{MeOH} \rightleftharpoons \mathrm{MTBE}
$$

This is a reversible and exothermic reaction. The reaction takes place in liquid phase at $25^{\circ} \mathrm{C}$ [6]. The feed conditions for the production of MTBE based on compounds are summarized in Table 1 . The feed is introduced to the column at 1 atm and $300 \mathrm{~K}$ with a flowrate of $100 \mathrm{kmol} / \mathrm{hr}$. The pressure drop across the column is assumed to be negligible.

Table 1

Design targets and product specifications

\begin{tabular}{cccc}
\hline Component & Feed & Distillate & Bottom \\
\hline Isobutene $\left(\mathrm{C}_{4} \mathrm{H}_{8}\right)$ & 0.7 & 0.98 & - \\
Methanol $\left(\mathrm{CH}_{4} \mathrm{O}\right)$ & 0.3 & - & - \\
MTBE $\left(\mathrm{C}_{5} \mathrm{H}_{12} \mathrm{O}\right)$ & 0.0 & - & $>0.8$ \\
\hline
\end{tabular}

To quantify the design and control performance of the RD system, the design-control multi-objective function is defined as follows:

$$
f_{o b j}=\min \left(J_{1}, J_{2}, J_{3}, J_{4}, J_{5}, J_{6}\right)
$$

where, $J_{1}=$ energy consumption associated with the process, and $J_{6}=$ total $\mathrm{CO}_{2}$ footprint per $\mathrm{kg}$ feed. These parameters are steady state performance and sustainability metrics. $J_{2}=$ integral absolute error of the controlled variables, $J_{3}=$ total variation of the manipulated variables. These parameters characterize the closed-loop performance.

$$
\begin{gathered}
J_{2}=I A E=\int_{0}^{\infty}\left|y-y_{s p}\right| d t \\
J_{3}=T V=\sum_{i=1}^{\infty}\left|u_{i+1}-u_{i}\right|
\end{gathered}
$$

$J_{4}=$ Relative Gain Array (RGA), which indicates the degree of loop interactions for a multi input multi output (MIMO) process. $J_{5}=$ Niederlinski Index $\left(N_{I}\right)$, a scaler, is a measure of system stability when integral controllers are used for the control loops. These parameters validate the appropriateness of the control structure. Note that for a $2 \times 2$ system, $N_{I}$ and RGA are clearly related because $N_{I}=1 /(1,1)_{R G A}$. Hence, the condition is that both have to be positive.

Since, there are 3 compounds and 1 reaction, the reactive system can be expressed by 2 elements [7]. The element matrix for the reactive system is given in Table 2. Here, the light key element (A) is selected to be isobutene, and the heavy key element (B) is methanol. For the reactive VLE calculation, the pure component properties (critical properties, molecular weight, boiling and melting points) are retrieved from ICAS Database[8].

Table 2

The element matrix for MTBE system

\begin{tabular}{cccc}
\hline & \multicolumn{3}{c}{ Component } \\
\hline Element & i-butene & MeOH & MTBE \\
\hline $\mathrm{A}$ & 1 & 0 & 1 \\
$\mathrm{~B}$ & 0 & 1 & 0 \\
\hline
\end{tabular}

Wilson thermodynamic model and SRK equation of state are used for prediction of the liquid phase and vapor phase behavior respectively. The resulting $T-$ $W_{A}^{l}-W_{A}^{v}$ phase diagram is shown in Fig. 1.

Next, the reactive distillation design variables (number of stages, reflux ratio, feed location) are determined using the driving force approach [2]. Fig. 2 shows the driving force diagram. Moving away from the maximum driving force towards lower values, the

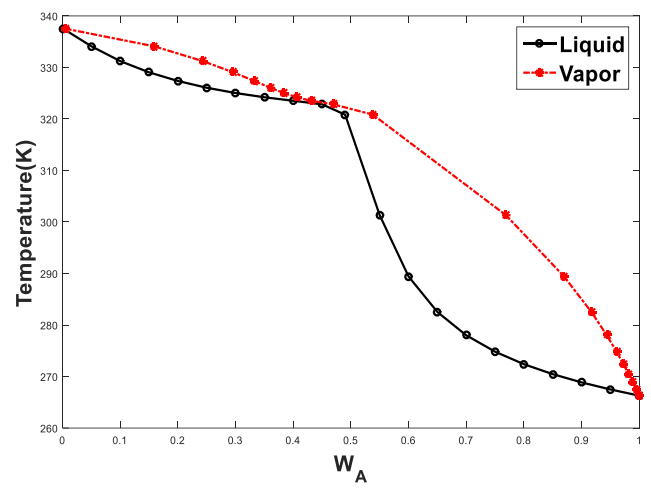

Fig. 1: $T-W_{A}^{l}-W_{A}^{v}$ phase diagram for MTBE system.

separation becomes more difficult. On the other hand, moving towards maximum driving force, the separation becomes easier due to larger difference between vapor and liquid phase compositions.

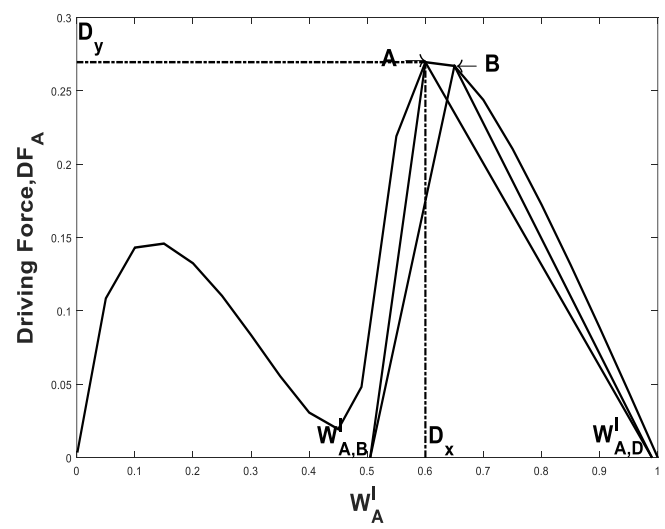

Fig. 2: Reactive driving force diagram for MTBE system.

Therefore, from a process design perspective, the reactive distillation column should be designed at the maximum driving force for minimum energy consumption [9]. Note that, in the diagram, point A denotes the location for the column design at the maximum driving force, whereas Point $\mathrm{B}$ denotes the location of the driving force for the alternative design (design parameters are summarized in Table 3). Operating area is defined by selecting light key element distillate composition $\left(W_{A}^{D}\right)$ and light key element bottom composition $\left(W_{A}^{B}\right)$. To do so, the light key element liquid mole fraction is considered as follows: When $x_{1}=1$ (pure isobutene), $x_{2}=x_{3}=0$, then $W_{A}^{l}=1$ and $W_{B}^{l}=0$. When $x_{2}=1$ (pure methanol), $x_{1}=x_{3}=0$, then $W_{A}^{l}=0$ and $W_{B}^{l}=1$. 
Therefore, when $x_{3}=1$ (pure MTBE), $x_{1}=x_{2}=0$, then $W_{A}^{l}=0.5$ and $W_{B}^{l}=0.5$.

Consequently, distillate $\left(W_{A}^{D}\right)$ and bottom $\left(W_{A}^{B}\right)$ are selected to be 0.99 and 0.5 on the $x$-axis of the reactive driving force diagram based on $W_{A}^{l}$ element composition. The points $D_{x}$ and $D_{y}$ corresponding to the location and size of the maximum driving force are identified and consequently the slopes of the operating lines are calculated. These correspond to the minimum reflux ratio $\left(R R_{\text {min }}\right)$ and reboil ratio $\left(R B_{\text {min }}\right)$. Actual $R R$ and $R B$ values are obtained after multiplying the minimum $R R_{\min }$ and $R B_{\text {min }}$ by 1.2 . After that, the slopes of the operating lines are determined. In this case study, the number of stages $(N)$ is not known; therefore, the reactive McCabe-Thiele method is applied. The total number of stages includes the number of the reactive stages plus the reboiler and the condenser (the two non-reactive stages). As mentioned above, Table 3 presents the reactive distillation column design parameters at the maximum driving force. The result of application of reactive McCabe-Thiele method is shown in Fig. .

Table 3

Summary of design parameters

\begin{tabular}{cccc}
\hline Design & $\begin{array}{c}\text { Number of } \\
\text { stages }\end{array}$ & Feed stage & Reflux ratio \\
\hline $\begin{array}{c}\text { Design- } \\
\text { control } \\
\text { solution }\end{array}$ & 6 & 2 & 3.88 \\
$\begin{array}{c}\text { Alternative } \\
\text { design }\end{array}$ & 6 & 3 & 5 \\
\hline
\end{tabular}

\subsection{Control structure verification}

In order to verify the control structure (controlled variables $(y)$ are the top and bottom compositions of isobutene and MTBE respectively; and the manipulated variables $(u)$ are the reflux rate and the reboiler duty), the linearized model of the process, i.e., the state-space model is obtained and the steady state gain matrix is constructed for the $2 \times 2$ system. After that, the relative gain array $(R G A)$ and Niederlinski index $\left(N_{I}\right)$, to verify the extent of loop interactions, are calculated as listed in Table 4 . It is found that the loop

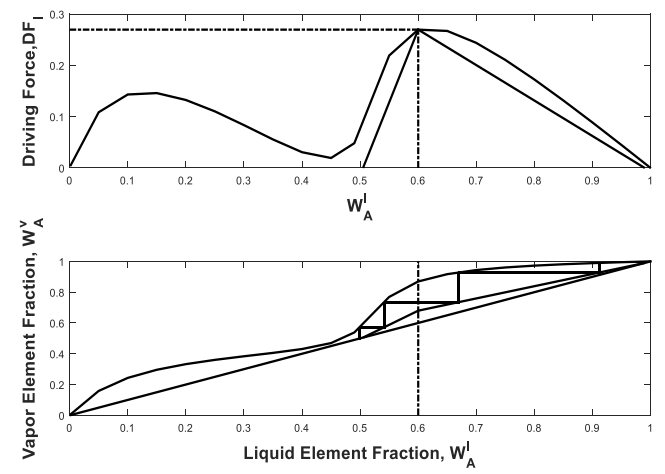

Fig. 3: Reactive McCabe-Thiele diagram for RD column design. interactions are minimal, since diagonal values are close to unity $\left(N_{I} \approx 1\right)$. Also the system is stable due to $N_{I}$ being positive.

\section{Dynamic analysis}

In order to evaluate dynamic open-loop and closed-loop performance, $+10 \%$ step disturbance is introduced through isobutene feed flow rate. At first the open-loop responses of the system to the disturbance has been determined as shown in Fig. 4 .

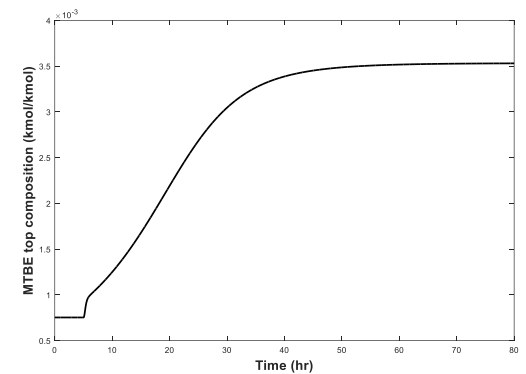

A

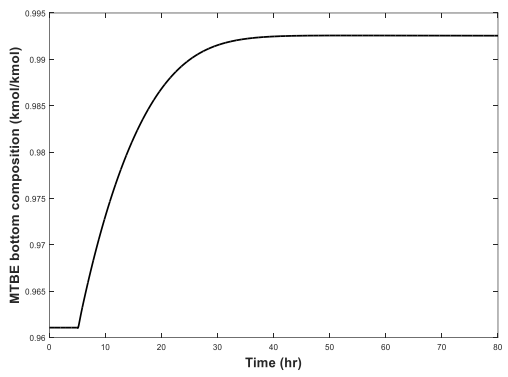

B

Fig. 4: Open-loop response of the optimal design control solution to step change in feed flow rate: A) top; B) bottom.

Next, using the state space model of the process, the closed loop simulation under MPC is performed which is shown in Fig. 5. For the MPC simulation, plant inputs are as follows: condenser duty - $Q_{c}$, reflux mass flow rate - $\mathrm{R}(\mathrm{kg} / \mathrm{hr})$, reboiler duty $-Q_{R}$, distillate mass flow rate $-\mathrm{D}(\mathrm{kg} / \mathrm{hr})$, bottoms mass flow rate B $(\mathrm{kg} / \mathrm{hr})$, and feed molar flow rate $(\mathrm{kmol} / \mathrm{hr})$. Plant outputs are as follows: column pressure (stage 1) - $\mathrm{P}$ (atm), mole fraction of the distillate of interest - $x^{D}$, mole fraction of the bottoms of interest $-x^{B}$, reflux drum liquid level - Rlev (m), and sump liquid level Slev (m). MPC controller is designed in such a way that the nominal set point for all the controlled and manipulated variables is set at $50 \%$. The simulation is run for 25 hours with a sampling time of 30s. The weights on all the manipulated variables are as follows: $\left[\begin{array}{llll}0 & 0 & 0 & 0\end{array}\right]^{T}$, since there is no reason to keep the manipulated variables at their set points. The inequality constraints are enforced through setting up a limit for the rate of change of manipulated variables. The relative weights are kept the same for all the manipulated variables. The weights on the controlled variables are as follows: $\left[\begin{array}{llllll}10 & 1 & 1 & 0.1 & 0.1\end{array}\right]^{T}$. Note that 
the relative weights are a measure to assign importance for keeping the controlled variables at the set point. For example, MPC controller assigns 10 times more importance to keep the distillate and bottom product compositions at their set points compared to drum level or sump level. Analogously, maintaining column pressure at the set point is given 100 times more importance than maintaining sump level, since, the column pressure must be regulated tightly for safe operation. Finally, the prediction horizon is set to be $30 \mathrm{~min}$ which is large enough to make the controller performance insensitive to further increases of the prediction horizon. The control horizon is set to be 4 min which is kept small to reduce computational effort.

Finally, the values of the parameters included in the performance objective function (Equation 1) are calculated. The results are presented in Table 4.

\section{Comparison with RD design not at maximum driving force}

In order to establish the appropriateness of the design-control solution under MPC, an alternative reactive distillation column design which is not at the maximum driving force, is selected for comparison. For the purpose of comparison, the number of stages is kept the same for all cases. Feed locations, reflux and boil-up ratios are varied and the same control structure and controlled variables as the ones in the maximum driving force design are used for the consistency of the comparison. The selected design alternative is summarized in Table 3. Following the steps as for the design-control solution, the rigorous steady state simulation is performed to check if the alternative design meets the design target. After that, the $R G A$ and $N_{I}$ values for the alternative designs are summarized in Table 4. Next, MPC controller under same tuning parameters as for the design-control solution is used for closed-loop simulation which is shown in Fig. . Note that the disturbance scenario is kept the same as for the design-control solution.
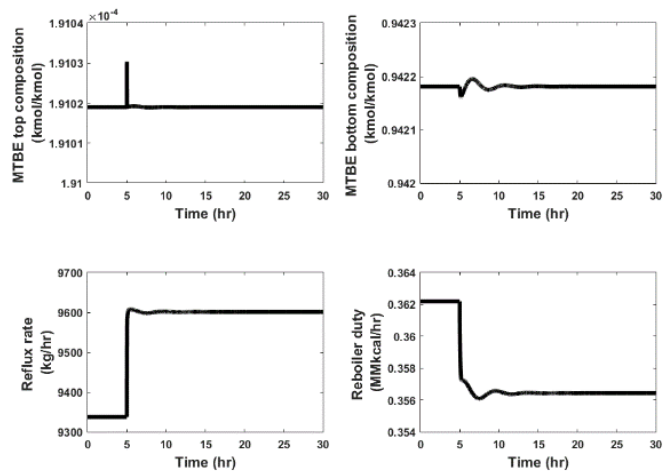

Fig. 5: Close-loop response of the optimal design control solution for step change in feed flow rate.
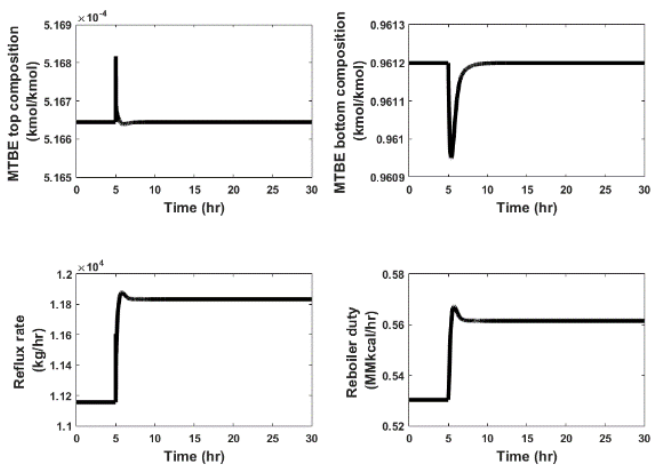

Fig. 6: Close-loop response of the alternative design for step change in feed flow rate.

Finally, the objective function values for both the design-control solution and the alternative design under MPC are summarized in Table 4. The dynamic responses show that the alternative design takes longer time to settle, and experiences larger process upset.

Table 4

Performance objective function values for design-control solution and the alternative design

\begin{tabular}{|c|c|c|c|c|c|c|c|c|c|}
\hline Design & $J_{1}[\mathrm{~kW}]$ & $J_{2 D}[\mathrm{hr}]$ & $J_{2 B}[\mathrm{hr}]$ & $J_{3 D}$ & $J_{3 B}$ & \multicolumn{2}{|c|}{$J_{4}$} & $J_{6}$ & $J_{6}\left[\mathrm{CO}_{2} \mathrm{eq} / \mathrm{kg}\right.$ feed $]$ \\
\hline $\begin{array}{l}\text { Design-control } \\
\text { solution }\end{array}$ & 1717.33 & $6.2 \mathrm{E}-10$ & 4E-05 & 264.4 & 0.0062 & {$\left[\begin{array}{c}1.26 \\
-0.26\end{array}\right.$} & $\left.\begin{array}{c}-0.26 \\
1.26\end{array}\right]$ & 0.791 & 0.1952 \\
\hline Alternative design & 2101.26 & $1.63 \mathrm{E}-08$ & 2.57E-04 & $1.13 \mathrm{E}+03$ & 0.0422 & {$\left[\begin{array}{c}-1.58 \\
2.58\end{array}\right.$} & $\left.\begin{array}{c}2.58 \\
-1.58\end{array}\right]$ & -0.687 & 0.2309 \\
\hline
\end{tabular}

${ }^{\mathrm{a}} J_{2}$ and $J_{3}$ are calculated for both the top and bottom control loop.

\section{Conclusion}

MPC control performance is analyzed for the reactive distillation system that was designed based on driving force approach. The quantified results verify that the design-control solution, which is designed at the maximum driving force, demonstrates superior controllability under supervisory controller, i.e., MPC; compared to other design alternatives. Therefore, it is confirmed that by going away from the maximum driving force, the control of the reactive distillation process becomes more difficult. 


\section{Acknowledgments}

The authors would like to acknowledge the help of Dr. Anjan Tula at Zhejiang University, for the carbon footprint calculation.

\section{References}

[1] M. C. Georgiadis, M. Schenk, E. N. Pistikopoulos, and R. Gani, "The interactions of design, control and operability in reactive distillation systems," in Computers and Chemical Engineering, May 2002, vol. 26, no. 4-5, pp. 735-746, doi: 10.1016/S0098-1354(01)00774-8.

[2] E. Bek-Pedersen and R. Gani, "Design and synthesis of distillation systems using a driving-force- based approach," Chem. Eng. Process. Process Intensif., vol. 43, no. 3, pp. 251-262, Mar. 2004, doi: 10.1016/S0255-2701(03)00120-X.

[3] S. S. Mansouri, J. K. Huusom, R. Gani, and M. Sales-Cruz, "Systematic integrated process design and control of binary element reactive distillation processes," AIChE J., vol. 62, no. 9, pp. 3137-3154, Sep. 2016, doi: 10.1002/aic.15322.

[4] M. Francisco, P. Vega, and H. Álvarez, "Robust Integrated Design of processes with terminal penalty model predictive controllers," Chem. Eng. Res. Des., vol. 89, no. 7, pp. 10111024, Jul. 2011, doi: 10.1016/j.cherd.2010.11.023.
[5] S. S. Bahakim and L. A. Ricardez-Sandoval, "Simultaneous design and MPC-based control for dynamic systems under uncertainty: A stochastic approach," Comput. Chem. Eng., vol. 63, pp. 66-81, Apr. 2014, doi: 10.1016/j.compchemeng.2014.01.002.

[6] A. M. Al-Jarallah, A. K. K. Lee, and M. A. B. Siddiqui, "Kinetics of methyl tertiary butyl ether synthesis catalyzed by sulphuric acid," Chem. Eng. J., vol. 39, no. 3, pp. 169174, Dec. 1988, doi: 10.1016/0300-9467(88)80024-8.

[7] E. S. Pérez Cisneros, R. Gani, and M. L. Michelsen, "Reactive separation systems - I. Computation of physical and chemical equilibrium," Chem. Eng. Sci., vol. 52, no. 4, pp. 527-543, 1997, doi: 10.1016/S0009-2509(96)00424-1.

[8] T. L. Nielsen, J. Abildskov, P. M. Harper, I. Papaeconomou, and R. Gani, "The CAPEC database," J. Chem. Eng. Data, vol. 46, no. 5, pp. 1041-1044, Sep. 2001, doi: 10.1021/je000244z.

[9] T. Lopez-Arenas, S. S. Mansouri, M. Sales-Cruz, R. Gani, and E. S. Pérez-Cisneros, "A Gibbs energy-driving force method for the optimal design of non-reactive and reactive distillation columns," Comput. Chem. Eng., vol. 128, pp. 5368, Sep. 2019, doi: 10.1016/j.compchemeng.2019.05.024.

CBangladesh Uni. of Engg. \& Tech. 